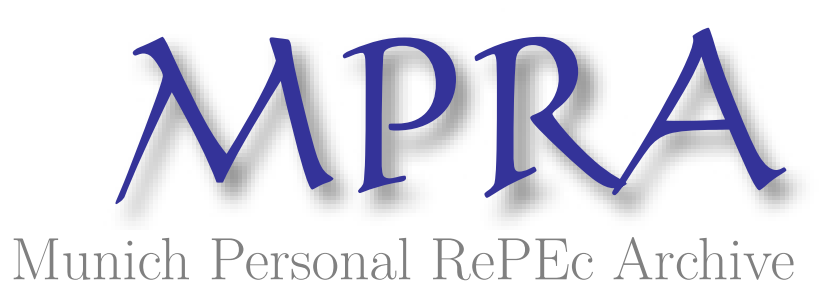

\title{
Transparency between banks and their customers. information needs and public intervention
}

Caratelli, Massimo

January 2005

Online at https://mpra.ub.uni-muenchen.de/37108/

MPRA Paper No. 37108, posted 05 Mar 2012 12:19 UTC 


\title{
Transparency between banks and their customers. Information needs and public intervention
}

\author{
Massimo Caratelli \\ Department of Management and Law \\ Rome 3 University \\ ma.caratelli@uniroma3.it
}

Working paper, January 2005

\begin{abstract}
Factors such as the spread of complex financial instruments, the broadening of available alternatives, have fostered more decisive public intervention in support of transparency between banks and their customers. The effectiveness of the public intervention measures depends on the actual information needs of consumers. The aim of this paper is to assess the extent and characteristics of the information needs, by analysing the decision-making processes. High financial sacrifice, high perceived risks, considerable differences between the available alternatives, seem to justify an intense search for information. The precision with which information is searched for would be reduced as an effect of financial experience and knowledge, an perceived excessive complexity of the service and stringent time pressure.
\end{abstract}

\section{Introduction}

Factors such as the spread of complex financial instruments, the broadening of available alternatives, the general interest in making sure that financial activities are conducted efficiently and effectively, the opening up of markets to international competition, have fostered more decisive public intervention in support of greater transparency between banks and their customers.

The arguments in favour of greater disclosure are essentially based on the role played by transparency in the efficient allocation of resources and in the efficacy of the mechanisms for coordinating economic activities in a market system.

The regulations issued to this effect have concerned two groups of stakeholders: the banks, as the addressees of the established conduct requirements, on the one hand, and the consumers of financial services, who are the beneficiaries of the protection afforded by such conduct, on the other hand. In particular, the new transparency standards require that financial intermediaries' conduct should be aimed at rebalancing the information asymmetry typical of relations between banks and their customers, by transferring to the latter information on the characteristics and the general conditions of purchase of the services provided.

The effectiveness of the public intervention measures, of course, depends on the correctness of the underlying assumption that customers are interested in 
receiving the information contents transmitted to them; in short, it depends on the actual information needs of consumers.

The aim of this paper is to assess the extent and characteristics of the information needs, by analysing the decision-making processes and the manner in which knowledge is built up and used, with respect to the purchase of financial services.

Paragraphs 2 and 3 introduce the reasons that may convince a consumer to purchase a financial service. Paragraph 4 continues with a description of the decision-making process and its constituent phases. Paragraph 5 features a classification of the purchasing processes, based on the time and effort required to make a choice. Paragraph 6 sets out an estimate of the information needs when arranging a mortgage or taking out consumer credit. Lastly, paragraph 7 provides an overview of the main results achieved.

\section{Individual needs and financial requirements}

A need may be defined as a necessity, a request coming from within our body, the satisfaction of which is necessary to survive or to maintain a good psychophysical balance. Of course, not all needs are strictly necessary to survive, but by satisfying them we do live better lives (Dalli D., Romani S., 2000, p. 133).

Traditionally speaking, needs are classified according to type and, at times, can be hierarchically organised. The classifications with the greatest consensus in literature are those by Maslow (1943, 1954), Murray $(1938,1955)$ and McGuire (1974, 1976).

There is a consensus of opinion, in literature, that consumers make use of financial services primarily in order to:

a. regulate trade;

b. build up savings (intended here as a source for future consumption, by oneself or by one's nearest and dearest);

c. finance expenditure beyond one's present means;

d. manage one's financial assets and/or liabilities in an integrated manner, with a view to ensuring that the purposes set out in letters (b) and (c) are pursued most effectively.

Therefore, the function of financial services becomes the efficient transfer of resources in space and time; which transfer is necessary to "finance" the purchasing of products and services deemed appropriate to satisfy one's needs. According to this view, satisfying one's needs is the ultimate motive that justifies purchasing a financial service. It ensues that, generally speaking, a consumer's interest in a financial service is of a reflexive nature (Tagliavini G., 1990, p. 110).

The following table 1.1 shows the financial needs of a typical consumer. The table is the result of the application of Maslow's hierarchy of needs to the individual life-cycle theory. 
Table 1.1 - General needs and financial requirements based on Maslow's hierarchy of needs

\begin{tabular}{|c|c|}
\hline $\begin{array}{l}\text { Class of need } \\
\text { (in growing order of } \\
\text { importance) }\end{array}$ & Associated financial requirements \\
\hline Physiological & $\begin{array}{l}\text { - availability of payment instruments } \\
\text { - indebtedness (for necessity) }\end{array}$ \\
\hline Safety and belonging & $\begin{array}{l}\text { - } \text { paying back debts } \\
\text { - } \text { keeping up one's lifestyle } \\
\text { - } \text { protecting one's assets from inflation } \\
\text { - } \text { buying a first home } \\
\text { - } \text { paying into a supplementary pension scheme } \\
\text { - } \quad \text { saving for unforeseen circumstances }\end{array}$ \\
\hline Esteem & $\begin{array}{l}\text { - } \text { improving one's lifestyle } \\
\text { - } \text { early retirement } \\
\text { - } \quad \text { paying less tax } \\
\text { - } \quad \text { indebtedness (for convenience and comfort) }\end{array}$ \\
\hline Self-actualisation & $\begin{array}{l}\text { - financial planning for training objectives } \\
\text { - financial planning for setting up and managing } \\
\text { an independent business }\end{array}$ \\
\hline
\end{tabular}

Source: based on Maslow A.H. (1943)

The application of Maslow's hierarchy of needs to the individual life-cycle theory makes it possible to appreciate how a consumer's scale of purchasing priorities may develop in time. Maslow's work is valuable for putting the matter in context. It is less useful, however, when making a detailed analysis of specific behaviours for forecasting purposes. There are, in fact, innumerable examples of behaviours that are inconsistent with the hierarchy of needs.

\section{The relationship between need and motivation}

The existence of an unsatisfied need is a prerequisite for motivation to manifest itself. Motivation, in fact, can be described as the drive to act in order to accomplish a certain objective, namely, that of adequately satisfying a perceived need.

Satisfying a need requires the implementation of a decision-making process, according to a series of sequentially ordered steps (Dalli D., Romani S., 2000, p. 134; Engel J.F., Blackwell R.D., Miniard P.W., 1993). Control over each step is proportional to the intensity of one's motivation (see Rheinberg F., 2003, pp. 177193): intensity of motivation, in fact, can affect the time, commitment and financial resources an individual is willing to invest to satisfy a need (Dalli D., Romani S., 2000, p. 155). 


\section{The decision-making process}

Once a state of need has been perceived, step one of the decision-making process kicks in. This concerns the search for alternatives capable of achieving satisfaction.

To overcome the state of stress, consumers start by searching among their own memories for any relevant information (internal search). When they realise that their own knowledge is insufficient to ensure a satisfactory outcome (Schmidt J.B, Spreng, R.A., 1996, p. 246), they turn to additional information from other sources (external search). These external sources may include information provided by the supplier or dealer or by independent organisations. Other information may be obtained through one's personal contacts or from a first-hand examination of the service (Olshavsky R.W., Wymer W., 1995).

In step two of the decision-making process, the available alternatives are assessed. This operation is typically effected based on certain decision-making rules. The function of these rules is to help the consumer sort the alternatives in order of preference.

Once the assessment has been completed, the next step is the decision to purchase and use the service.

The last step in the decision-making process is the post-use phase: after having used the service, consumers evaluate whether or not it meets their expectations.

\subsection{The decision-making rules}

The rules generally adopted when making a choice can be grouped into two large categories: «compensatory» and «non-compensatory» rules. The principal difference between the two types of rules is whether or not the values assigned to the different attributes of the choice alternatives can be "balanced" (Rumiati R., Bonini N., 2001, p. 154).

Compensatory rules are so called because they help the consumer conclude that the best option is the one wherein one or more appreciable attributes trade off - or «compensate» - against other less desirable attributes. The additive rule is an example of compensatory rule (see formula 1.1$)^{1}$.

\footnotetext{
${ }^{1}$ Other examples of compensatory rules are: the equal weight rule, the additive difference rule, the majority of confirming dimensions rule, the number of good and bad features rule. For more information, reference should be made to Bettman J.R., Luce M.F., Payne J.W. (1998, pp. 190192).
} 
Formula 1.1 - The additive rule: an example of compensatory rule

$$
V a=\sum_{i=1}^{n} W i \cdot V\left(X a_{i}\right)
$$

Va $=$ value of alternative $a$

$\mathbf{W}_{\mathbf{i}}=$ weight of the $\mathrm{i}$-th attribute

$\mathbf{X a}_{\mathbf{i}}=\mathrm{i}$-th attribute of alternative $a$

$\mathbf{V}\left(\mathbf{X} \mathbf{a}_{\mathbf{i}}\right)=$ assessment of the $\mathrm{i}$-th attribute of alternative $a$

The advantage in applying compensatory rules lies in the systematic assessment of the entire set of available information (accuracy of the decisionmaking process). The use of these rules, however, also has its disadvantages: first of all, they require complex judgements of value. Besides, the use of compensatory rules also requires a certain mental effort and a considerable amount of time to make a choice (Bettman J.R., Luce M.F., Payne J.W., 1998, p. 190).

Not all decision-making rules are of a compensatory nature. Non-compensatory rules, in fact, are so called because their application does not provide for any compensation between one or more 'attractive' attributes and other less attractive ones. The satisficing rule is an example of non-compensatory rule, whereby consumers define a level of acceptance for each attribute (Simon H.A., 1955). An alternative becomes unsatisfactory - and, therefore, to be discarded - when even only one of its attributes fails to exceed the assigned cutoff level ${ }^{2}$.

Non-compensatory rules are deemed to be easy to apply: it seems, in fact, that they require less mental effort, since it is unnecessary to weigh and compare the various features (Rumiati R., Bonini N., 2001, p. 164); furthermore, the volume of data to be examined is typically smaller, compared to the compensatory rules (Rumiati R., Bonini N., 1996, p. 105). The acknowledged simplicity of application of the non-compensatory rules, however, is set off by certain disadvantages: for example, these rules do not always ensure the invariance of the order of preference. It often occurs, in fact, that an alternative is discarded simply based on the order in which the options are examined.

The study of the selection processes has shown that consumers tend to select the decision-making rules on a case by case basis, based on factors such as, the characteristics of the problem (complexity of the decision-making process and time pressure), their personal experience and skills, and their envolvement with the product class (Bettman J.R., Johnson E.J., Payne J.W., 1991) ${ }^{3}$.

\footnotetext{
2 The non-compensatory nature of the rule is obvious: the good evaluation of an attribute, in fact, does not trade off against the value - slightly below the limit - of another feature. Further examples of non-compensatory rules are: the lexicographical rule, the elimination-by-aspects rule. For more information, reference should be made to Bettman J.R., Luce M.F., Payne J.W. (1998, pp. 190-192), Tversky A. (1972).

${ }^{3}$ Beach and Mitchell (1978) have claimed that the choice of any one rule is the result of a compromise between the desire to accurately analyse the available alternatives and the desire to minimise the effort related to the application of the rule. For more information see Bettman J.R.,
} 
By studying selection processes it has also been possible to infer that the compensatory and non-compensatory rules may be used in a complementary manner, within the same decision-making process (Rumiati R., Bonini N., 2001, p. 166). A typical combination of strategies comprises an initial phase, in which certain alternatives are discarded by applying non-compensatory rules, and a second phase in which the shortlisted alternatives are assessed with greater attention, by applying compensatory rules (Bettman J.R., Luce M.F., Payne J.W., 1998, p. 191). It can safely be assumed, when passing from one stage to another, that the analysed information increases in detail, while the strictness with which the consumer selects the significant attributes weakens.

It has been observed that the adoption of a multiphase strategy of this kind is typical of particularly complex decision-making dilemmas, featuring a relatively high number of both alternatives and attributes (Rumiati R., Bonini N., 1996, pp. 106-108).

\section{Types of decision making and the search for and processing of the information}

Not all decision-making processes are as complex as described in the foregoing paragraph, otherwise life would be spent entirely in making decisions.

Howard (1994) has classified decision-making processes into extensive and limited processes, based on the time and the effort required to make a choice.

Extensive decision-making processes entail a complex and difficult phase of searching for alternatives and defining the selection criteria. In the case of extensive processes, one can reasonably assume that consumers apply compensatory decision-making rules. Most of the studies conducted to date seem to support this theory (see Bettman J.R., Luce M.F., Payne J.W., 1998, p. 196), which features some important consequences, with respect to significant information. In particular, the consumers' preference for compensatory rules entails that individuals search for and process a large number of attributes and alternatives. Generally speaking, the information taken into account features a high degree of detail.

Limited decision-making processes consist in repeating consolidated cognitive and behavioural patterns, which are applied with hardly no variations. These processes require a limited effort and a short time frame and, in this case, one can reasonably assume that non-compensatory decision-making rules are applied. The preference accorded to non-compensatory rules implies that the consumer searches for and processes a limited number of attributes and alternatives, based on a selective analysis of the information. Typically, no detailed data is required.

In the case of limited processes, therefore, consumers do not appear to take account of the entire set of potentially available information, limiting themselves to a summary analysis of the data, probably related to the cost and quality of the service. It would also seem that special attention is given to those aspects deemed

Luce M.F., Payne J.W. (1998, p. 192), Johnson E.J., Payne J.W. (1985), Fennema M.G., Kleinmuntz D.N. (1995, pp. 21-24). 
capable of producing or preventing large-scale negative effects on the consumer's assets and social status. With respect to these aspects, significant information might include early termination conditions, credit bureas and credit registries reporting requirements ${ }^{4}$, the possibility of unilaterally amending the conditions of the relevant agreement, conditional insurance, and the risks related to the occurrence of catastrophic events.

The theory according to which customers pay special attention to the aspects deemed capable of producing or preventing large-scale negative effects on their assets and social status is consistent with the results obtained by Gollwitzer and Heckhausen (1987), who, especially with their studies on the motivational states of conscience, have shown that, when purchasing financial services, most individuals tend to essentially reflect on the negative (social and other) effects of an originally appealing desire (see Kahneman D., Tversky A., 1979; Goldberg J., von Nitzsch R., 2001; Lichtenstein S., Slovic P., Fischhoff B., Layman M., Combs B., 1978; Wyer R.S., Srull T.K., 1980).

Analysing the decision-making processes, Punj, Staelin (1983), Beatty, Smith (1987), Srinivasan, Ratchford (1991), Solomon (1996), Wells, Prensky (1996), Schmidt and Spreng (1996) have identified several of the factors capable of influencing the type of process applied, each time, by consumers, as follows:

- the required financial disbursements;

- the perceived risks (performance-related and of a social nature);

- any differences between the available alternatives on the market;

- their envolvement, with respect to the class of product;

- their financial knowledge and experience;

- the complexity of the service;

- information accessibility;

- any time-related restrictions imposing constraints on the decision-making processes.

In particular, by analysing these factors it would seem possible to estimate the decision-making process implemented by consumers, when purchasing financial services.

Following is a description of the effects apparently produced by the abovementioned factors on the motivation to search for and process information. The greater the motivation, the higher the chances of applying an extensive decision-making process.

Disbursements, or «perceived financial sacrifice», means the amount of interests and fees paid to the financial intermediary (see Schmidt J.B., Spreng R.A., 1996, p. 251). The maximum amount consumers are willing to spend depends on their interest in the product they are purchasing (enduring/situational envolvement with the product). The greater the financial sacrifice perceived by the individual, the greater is the fear to find, once the purchase has been made, that his or her money has been ill spent, having obtained only a modest benefit, compared to the resources invested and, generally speaking, compared to the

\footnotetext{
${ }^{4}$ The risk of undergoing significant restrictions, with respect to access to credit, and the use of certain payment instruments, in connection with reports being made to the credit bureas and credit registries, should stimulate the customer's interest in the abovementioned contents.
} 
opportunities offered by the environment in which he or she lives. One can reasonably assume that a significant financial sacrifice enhances the consumer's desire to accurately examine the available options, thus fostering the implementation of an extensive decision-making process.

Perceived risk means the uncertainty one may have with respect to the performance of the financial service, vis-à-vis the expected standards (Schmidt J.B., Spreng R.A., 1996, p. 251). The perceived risk is especially high in the case of new services and is of social relevance when the expectations of loss are very high. A high perceived risk should enhance the consumer's desire to accurately consider the alternatives, thus fostering the adoption of an extensive process.

Faced with perceived differences in the financial services, one can reasonably expect the consumer's fear of making a bad choice to increase (Schaninger C.M., Sciglimpaglia D., 1981). In this case too the customer would probably be committed to attentively searching for and assessing the alternatives.

The more or less lasting enduring/situational envolvement for financial services identifies another factor capable of positively influencing the desire to make an accurate analysis of the selection alternatives (Schmidt J.B., Spreng R.A., 1996, p. 250). Envolvement may be partly justified by an enduring/situational envolvement with product.

Experience and knowledge of financial services usually translate into a considerable amount of information for consumers, allowing them to reduce the amount of (cognitive and behavioural) resources needed in connection with the purchasing process (Srinivasan N., Ratchford B.T., 1991, p. 236; Andersson P., 2004). Experience and knowledge can also reduce the perceived risk, thus producing a further negative effect - indirectly, this time - on the consumer's desire to accurately examine the selection alternatives (Srinivasan N., Ratchford B.T., 1991, pp. 235-236; Andersson P., 2004). Experience and knowledge apparently foster the implementation of a limited decision-making process.

Satisfaction with previous purchases is also important: in particular, Punj and Staelin (1983) have shown how a satisfactory purchasing experience reduces both the perceived benefits of an accurate search for and assessment of alternatives and the perceived risk.

The (monetary and other) costs for identifying and comparing alternatives diminish the consumers' desire to conduct an in-depth analysis of the alternatives. The perceived costs seem to be influenced by the complexity of the financial services, information accessibility and time pressure (Bettman J.R., Luce M.F., Payne J.W., 1998, pp. 199-200). It can be assumed that a high perceived complexity, difficulty to access information and strong time pressure can foster the implementation of a limited decision-making process. One may reasonably expect that time pressure is more stringent in the case of enduring/situational envolvement with product.

Figure 1.1 provides a graphical overview of the relation between the factors capable of influencing the decision-making process, the benefits, the costs and the motivation to search for and process the information. Motivation represents the consumers' desire to commit themselves to an in-depth search for and assessment of the options. It can be assumed that benefits enhance motivation, while costs 
diminish it. The greater the intensity of motivation, the more likely the implementation of an extensive decision-making process.

Figure 1.1 - The search for and processing of information. Benefits, costs and motivation

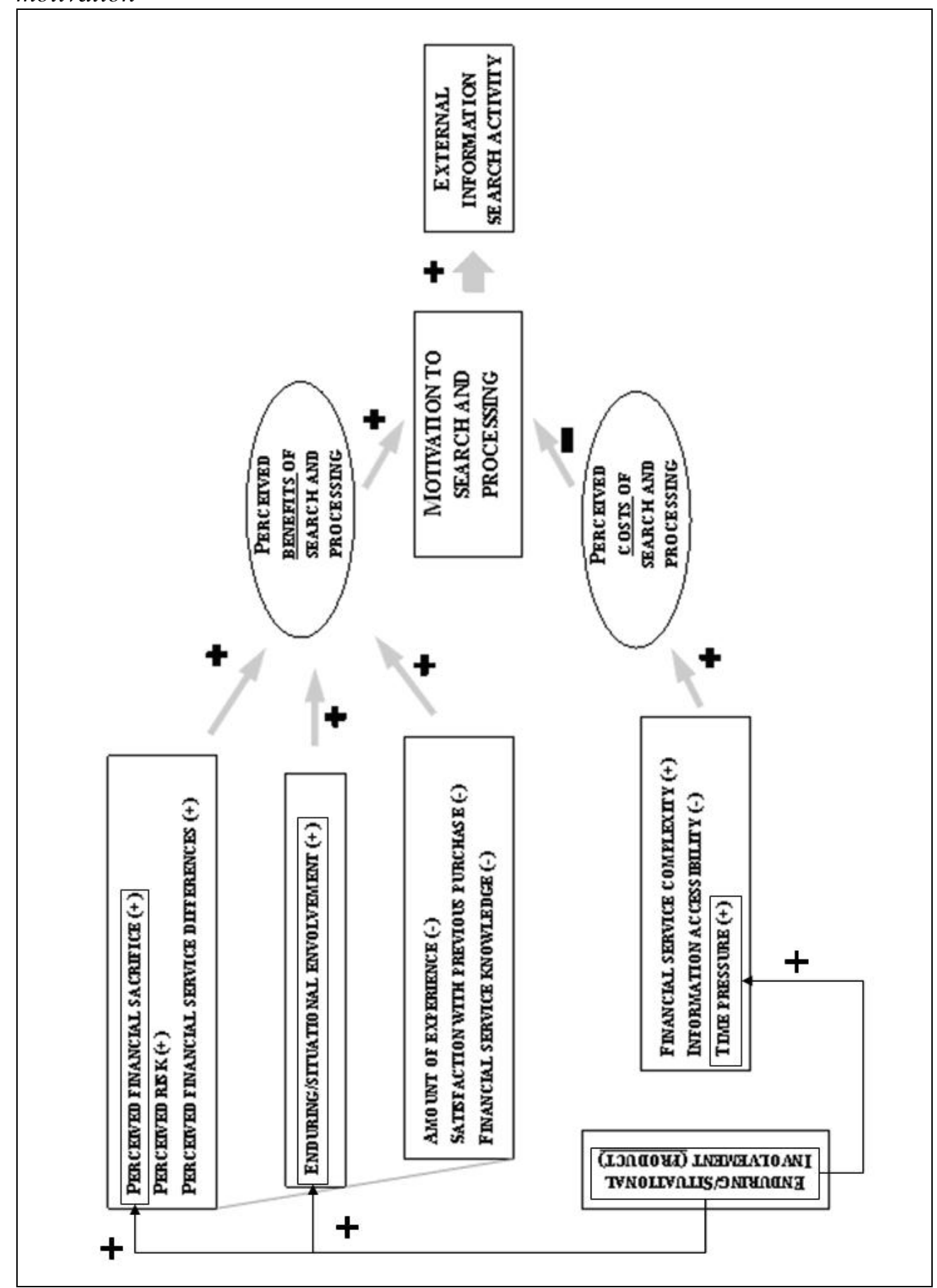

Source: based on Schmidt J.B., Spreng R.A. (1996, p. 248), Punj G.N., Staelin P. (1983, p. 367), Srinivasan N., Ratchford B.T. (1991, p. 234) 
Based on the foregoing, it can be maintained that there are various types of decision-making processes that an individual can identify in connection with the perception of a need. These types of processes differ based on the intensity with which consumers search for information, the characteristics of the information searched for (selectivity and detail), and the effort required to process it. Factors such as high financial sacrifice, high perceived risk, significant differences between the alternatives, high envolvement, seem to justify a committed search for and processing of information. On the contrary, financial experience and knowledge, the perceived excessive complexity of the service, the difficulty to access information and a strong time pressure tend to diminish the accuracy with which information is searched for and the time employed to make a choice.

These considerations feature two important consequences, with respect to the significant information:

- the greater the commitment and perseverance consumers are ready to willingly invest in the search for and processing of information, the greater the interest they will show in disposing of a large set of data (large number of alternatives and attributes taken into account), with a high level of detail (contents of the information);

- in the case of particularly complex decisions (i.e. characterized by a relatively high number of both alternatives and attributes), it is likely that consumers will adopt a multiphase strategy to assess the alternatives. In this case, they will take stock of the different degree of detail of the information they are interested in analysing, when passing from one phase to the other; moreover, the strictness with which the most significant attributes are selected should be weakened (number of alternatives and attributes taken into account).

These theories will now be applied to estimate the information needs of consumers of financial services. Based on the differences relating to functions of use, it was decided to omit a description of what takes place in the financial system at large and focus on specific and sufficiently representative banking business areas. The choice has fallen on the offer of medium-to-long term loans (mortgages) and consumer credit.

\section{The information needs of consumers of financial services}

Following is an analysis of the information needs of consumers of financial services. Two cases may be considered:

- mortgages;

- consumer credit loans.

The following sub-paragraph provides an overview of the information needs, in connection with mortgage transactions.

In the following pages the assumption is made of easy access to the available information. 


\subsection{Mortgages}

A mortgage is a medium-to-long term loan generally arranged to finance the purchase, construction or refurbishment of real estate property.

The size and term of the loan:

- highlight how taking out a mortgage is a choice capable of significantly affecting the borrower's economic and financial situation (high disbursements);

- justify the low frequency with which this service is purchased (low experience).

Both these observations refer to the significant envolvement, by consumers, in the phases required to select the service provider and define the characteristics of the loan: only a strong interest in purchasing this service, in fact, can justify the decision to undertake such a level of indebtedness; they also suggest a high perceived risk.

In consequence of the large amount of red tape associated with these transactions (banks require a great deal of documents to be produced and investigations made before granting the mortgage and making the funds available, under the law the mortgage deed must be drafted by a notary public, and the borrower is required to provide security to the financial intermediary) potential borrowers seem prepared to wait for, perhaps, a considerable length of time before receiving the money from the lender. Therefore, one may reasonably assume that time pressure is not particularly stringent, even though consumers are obviously concerned to complete the formalities as soon as possible and to be granted the money and the property in the shortest possible time.

A mortgage as such is not a particularly complex service. However, consumers find it hard to compare the numerous alternatives available on the market, all of which differ - more or less considerably - in terms of interest rates, currency, term and amortization schedule.

Graph 1.1 summarises the contents of this sub-paragraph, with respect to the factors (such as the required financial sacrifice and perceived risk) capable of influencing the type of decision-making process implemented by consumers when taking out a mortgage. 
Graph 1.1 - Motivation to search for and process information when taking out a mortgage

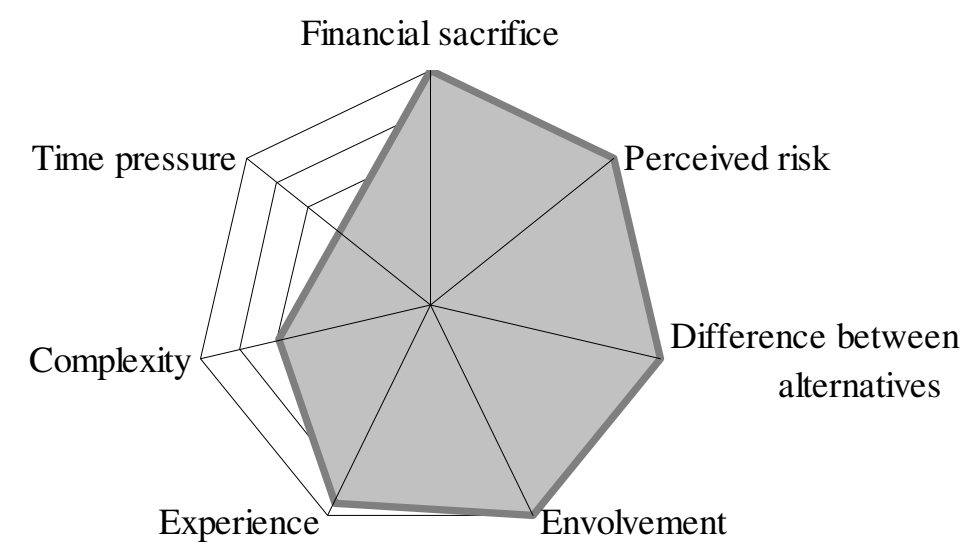

In the graph, the grey area approximates the inensity of the motivation to search for and process information. The area is rather large, which justifies the assumption that consumers apply an extensive decision-making process.

In the case of extensive processes, one can reasonably expect the use of compensatory decision-making rules. The preference here for compensatory rules means that consumers search for and process a considerable number of alternatives and attributes. The required information typically feature a high level of detail.

The difficulty inherent in an effective comparison between the numerous available options would suggest the adoption of multiphase decision-making strategies. In an initial, exploratory, phase consumers would probably apply particularly selective non-compensatory rules. They would hardly search for detailed information, but would be interested, first of all, in straightening out the purpose of the mortgage and its general characteristics (maximum and minimum mortgage borrowing, mortgage term, related fees and disbursements, repayment amount and frequency, role of the notary public and of the security). Later on, they would try to find out who the principal service providers are. The examination of the various alternatives would obviously involve the most visible 
market providers (importance of the image and reputation of the intermediary) ${ }^{5}$ or those which offer a positive past track record (based on direct or indirect experience). At this stage, consumers appear to be more interested in receiving synthetic cost indicator, with a view to making an initial comparison of the alternatives. The information collected here is essential for assessing whether to admit or discard each option and, if necessary, to alter one's general objectives, in terms, for example, of the amount of the loan and of the admissible financial sacrifice and time frame of the mortgage.

Once a shortlist of the alternatives has been made, consumers probably carefully compare the options, with respect to factors such as the strictly financial aspects, the quality of the service and an estimate of the performance risks. At this stage, the previously collected information should be supplemented with more detailed data.

Having regard to the strictly financial details of the service, the potential borrower would be interested in receiving detailed information on the expense items involved, such as the amount and frequency of the repayments, the mortgage term, the trends of the basic parameters involved, in the case of variable rate mortgage, the applied spreads, the arrangement fees and notarial fees, the insurance fees, the other charges and the relevant tax deductions (see Raynard R., Hinkley L., Williamson J., McHugh S., 2006). In order to examine the alternatives based on a criterion of efficiency, consumers would also like to receive detailed information as to the documents required in connection with the mortgage application, besides clarifications as to the procedures for registering and cancelling the mortgage, the legal formalities involved and providing additional security.

Having regard to the quality of the service, the potential borrower would probably be interested in receiving information relating to the mortgage amount, the maximum amount under a supplementary mortgage, repayment flexibility, conditional insurance, mortgage term and amortization schedule, the conditions relating to the sale of property concerned (the prohibition to sell before the term of the mortgage expires and the cumulative assumption of the mortgage). Other conditions deserving attention concern the amendment of the mortgage agreement and the early repayment of the loan; which information is useful to assess the flexibility afforded the customer in taking advantage of a possible drop in the interest rates.

Having regard to the estimate of the performance risks, consumers would probably like to receive historical data on the variation of the base parameters, besides information on how moratory interest is calculated, on any conditions allowing unilateral termination of the agreement by the lender and, generally speaking, on the consequences of the delay or failure to repay the loan on their assets and social status. Other information of interest could be the effects on the mortgage agreement of any unpleasant events occurring to the borrower (if borrower predeceases the term of the loan, or if he or she becomes temporarily

\footnotetext{
${ }^{5}$ For a description of the role played by brand names in financial services, see Munari L. (1995, p. 550).
} 
disabled or loses his or her job) or to the property encumbered by the mortgage (earthquake, floods, attacks) (see Williamson J., Ranyard R., Cuthbert L., 2000). Consumers would also like to receive information on the causes warranting amendments to the conditions of the mortgage agreement, to the extent the bank is unilaterally entitled to do so, of course.

\subsection{Consumer credit loans}

Consumer credit products consists in loans granted to applicants, who may use the money for any of the following purposes:

- to purchase goods and services for current consumption (food, medical services, clothing, travel);

- to purchase durable consumer goods (household appliances, furniture, consumer electronics, motor vehicles, boats);

- to invest in jewels, collectibles, financial activities or real estate property.

These loans can take the form of vehicle and point-of-sale financing, generic personal lending, revolving credit, with or without a card, and salary guaranteed loan schemes.

Consumer credit loan agreements can be concluded at either the premises of the bank or the specialist arranging the loan, or of the dealers where the goods/services are being purchased.

The consumer's desire to obtain the goods, or the sum of money to spend, explains his need for a fast loan approval; an urgency which can distract him, in part, from the characteristics of the service (see Kamleitner B., Kirchler E., 2006; Lewis A., van Venrooij M., 1995). The consumer's moderate interest in defining the characteristics of the service is also justified by other factors, such as the low management fees involved, limited customisation flexibility (due to fixed interest rates and level-payment amortization schedules, on a monthly basis) ${ }^{6}$ and the average frequency of purchase (average experience).

The limited customisation flexibility of the service highlights the simplicity of this product and the small differences between the alternatives available on the market. Revolving credit, salary-guaranteed loan schemes and personal loans feature a greater degree of differentiation. However, it is only rarely that the differentiation is such as to entail difficulties for consumers when comparing the alternatives.

The small amount of the loans is such that only a sizable reduction of the market rates would be able to considerably affect (and negatively so) the performance of the service. Consequently, the key components of the perceived risk are the conditions for contract termination ${ }^{7}$, and, generally speaking, how any

\footnotetext{
6 The desire to facilitate financial planning for buyers justifies the simplicity of the amortization schedules proposed by financial intermediaries. Furthermore, the prevalence of simple repayment schemes exemplifies the scarce attention by demand for complex instalment schemes and for the excessive customisation of loan agreements.

7 The failure to make even only one repayment may entitle the lender to unilaterally terminate the loan agreement. On top of this, the customer is also liable to end up in the list of bad payers and to be reported to the credit bureaus and credit registries, which rate the borrower's
} 
delays or the failure to repay the loan can affect the borrower's assets and social status. In the case of point-of-sale financing, the close link that exists between purchasing goods and applying for a loan also entails the customer's paying attention to the risks relating to the purchase contract and loan agreement (suffice it to mention, for example, the consumer exercising his right of withdrawal or any disputes arising with the seller). Therefore, it can be assumed that consumers perceive consumer credit loan transactions, overall, as medium or low risk operations (Williamson J., Ranyard R., Cuthbert L., 2000).

Graph 1.2 summarises the abovementioned arguments, with respect to the factors (such as the required financial sacrifice and the perceived risk) capable of affecting the type of decision-making process implemented by the consumer, with respect to consumer credit loan transactions.

creditworthiness and which share this information with the entire banking and financial system. At the end of the whole process, the outcome is a bad credit rating and further difficulties in obtaining credit in the future. 
Graph 1.2 - Motivation to search for and process information when respect to consumer credit

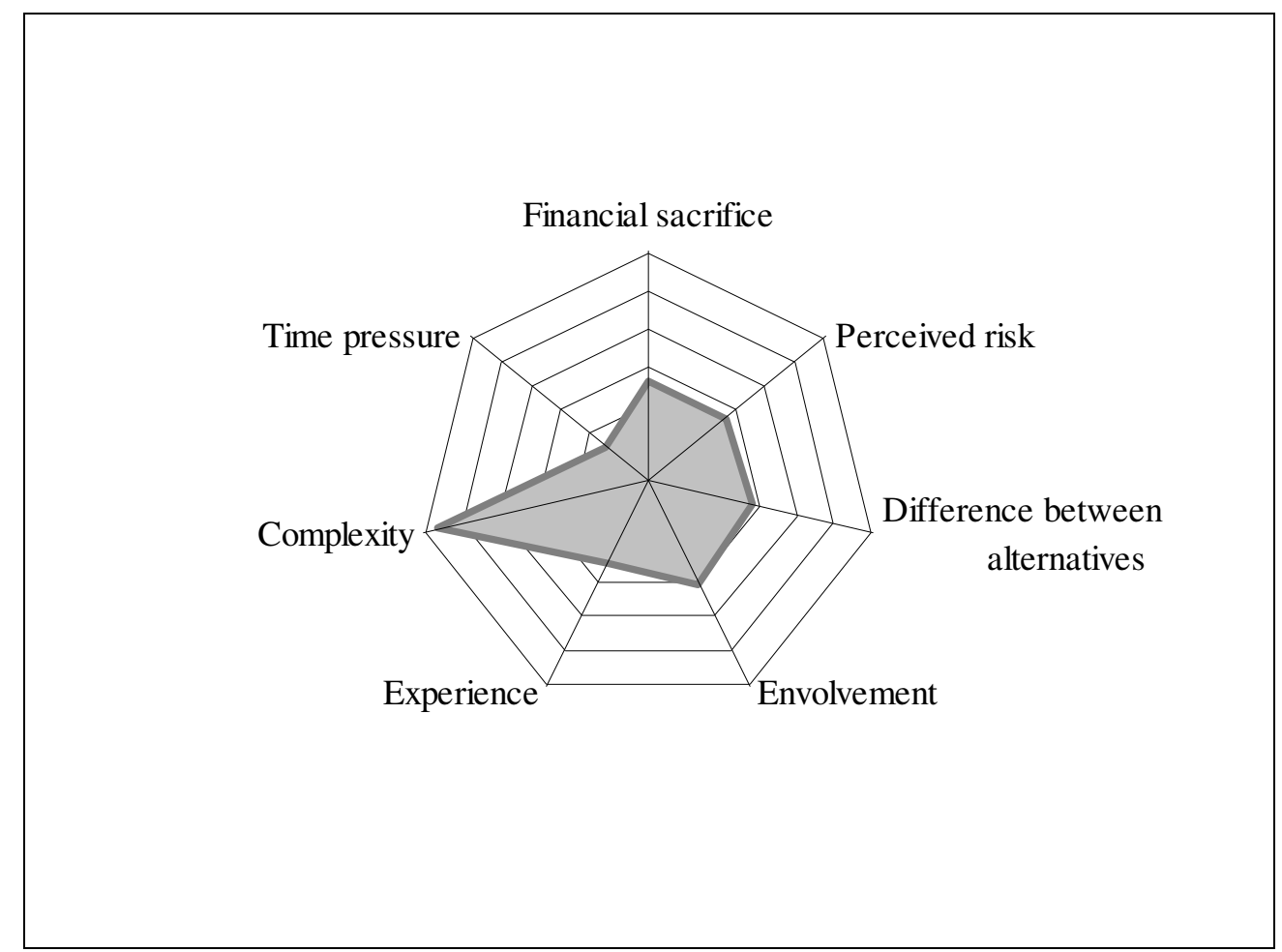

In the graph, the grey area approximates the intensity of the motivation to search for and process information. The area is rather small, which justifies the assumption that consumers apply a limited decision-making process.

In the case of limited processes, one can reasonably expect the application of a non-compensatory decision-making process. The preference for noncompensatory rules entails that consumers search for and process a limited amount of attributes and alternatives. In particular, consumers limit themselves to examining synthetic cost indicators; at the most, they might consider the repayment instalment amount in absolute terms (see Raynard R., Hinkley L., Williamson J., McHugh S., 2006). The consumers' focus would also seem to be on synthetic service quality indicators. Their desire to purchase the goods or obtain the money to spend would seem to suggest that the loan approval speed is a synthetic quality indicator.

Customers would also seem to be interested in receiving information indicating which documents should be attached to the loan application. The timely availability of this information, in fact, would allow them to speedily comply with the required formalities and obtain either the goods or the money within a 
reasonable time frame. Reducing the loan approval time, in the customers' eyes, is tantamount to improving the quality of the service ${ }^{8}$.

Consumers also seem to focus on those aspects deemed capable of producing or preventing significant negative effects on their assets or their social status. With respect to this, significant information might include early termination conditions, credit bureas and credit registries reporting requirements, the possibility of unilaterally amending the conditions of the relevant agreement, conditional insurance, and the risks related to the occurrence of catastrophic events.

Only rarely do consumers find it hard to effectively compare the available alternatives. This seems to suggest the adoption of single-phase decision-making strategies.

\section{Conclusions}

Factors such as the spread of complex financial instruments, the broadening of available alternatives, the general interest in making sure that financial activities are conducted efficiently and effectively, the opening up of markets to international competition, have fostered more decisive public intervention in support of greater transparency between banks and their customers.

The new transparency standards require that financial intermediaries' conduct should be aimed at rebalancing the information asymmetry typical of relations between banks and their customers, by transferring to the latter information on the characteristics and the general conditions of purchase of the services provided.

The effectiveness of the public intervention measures, of course, depends on the correctness of the underlying assumption that customers are interested in receiving the information contents transmitted to them; in short, it depends on the actual information needs of consumers.

The aim of this paper is to assess the extent and characteristics of the information needs, by analysing the decision-making processes: in particular, the greater the commitment and perseverance consumers are ready and willing to invest in the search for and processing of information, the greater appears to be their interest in receiving large amounts of detailed information. This information should concern the costs and quality of the service and an estimate of the relevant performance risks.

Factors such as high financial sacrifice, high perceived risks, considerable differences between the available alternatives, a high degree of envolvement, seem to justify an intense search for information and a commitment in processing this information. The precision with which information is searched for and the time dedicated to making a choice would be reduced as an effect of financial experience and knowledge, an perceived excessive complexity of the service and stringent time pressure.

\footnotetext{
${ }^{8}$ Consistently with this theory, many financial intermediaries have decided, in recent years and for small loan applications, to considerably cut down on the amount of documents required to be produced by the applicant. In the customer's eyes, this is tantamount to a considerable reduction of the loan approval time.
} 
In the case of decision-making processes that require a limited effort and time pressure it can reasonably be assumed that there has been a thorough selection of the available information.

In developing this paper, and in connection with the differences emerging in terms of significant information, it was decided to omit a description of what takes place in the financial system at large and focus on specific and sufficiently representative banking business areas. Consequently, we have proceeded in identifying the information needs with respect to taking out mortgage and consumer credit loans.

Information needs, however, are not the only factor capable of explaining the efficacy of the standard-setting measures. The capacity of these measures of accomplishing their purpose, in fact, depends on whether or not another two assumptions can be made: (i) that consumers are capable of receiving the contents transmitted to them, and (ii) that they can understand and make effective use of them.

The former assumption necessarily focuses on the availability of information and on the delicate choice of the proper information transmission channels, access to which must be easy and cheap.

The latter assumption focuses on the intelligibility of the information as communicated. Clearly, in fact, for any information to be effective, the notices issued by the bank - in accordance with the standards - must be built on the basis of expressive actions for the addressee-consumer, i.e. they must be able to understand their meaning and, therefore, interpret it correctly. The addresseeconsumers' inability to construe the meaning of the information renders the banks' action useless and, consequently, threatens the efficacy of the public intervention measures.

Based on this interpretational framework, a possible suggestion for future research could concern an investigation into the manner in which the following affect the effectiveness of the public intervention measures:

- consumer preference, with respect to information transmission channels;

- the customers' capability of understanding the communicated information. 


\section{References.}

Andersson P, (2004), "Does experience matter in lending? A process-tracing study on experienced loan officers' and novices' decision behavior", in Journal of Economic Psychology, volume 25, n. 4, pp. 471-492

Beach L.R., Mitchell T.R., (1978), "A Contingency Model for the Selection of Decision Strategies", in Academy of Management Review, volume 3, n. 3, pp. 439-449

Beatty S.E., Smith S.M., (1987), "External Search Effort: An Investigation Across Several Product Categories", in Journal of Consumer Research, volume 14, n. 1, pp. 83-95

Bettman J.R., Johnson E.J., Payne J.W., (1991), "Consumer Decision Making”, in Robertson T.S., Kassarjian H.H. (Eds.), Handbook of Consumer Behavior, Prentice Hall, Englewood Cliffs, pp. 50-84

Bettman J.R., Luce M.F., Payne J.W., (1998), "Constructive Consumer Choice Processes", in Journal of Consumer Research, volume 25, n. 3, pp. 187-217

Dalli D., Romani S., (2000), Il comportamento del consumatore. Teoria e applicazioni di marketing, FrancoAngeli, Milan

Engel J.F., Blackwell R.D., Miniard P.W., (1993), Consumer Behavior, The Dryden Press, Chicago

Fennema M.G., Kleinmuntz D.N., (1995), “Anticipations of Effort and Accuracy in Multuattribute Choice", in Organizational Behavior and Human Decision Processes, volume 63, n. 1, pp. 2132

Goldberg J., von Nitzsch R., (2001), Behavioral Finance, John Wiley \& Sons Ltd., New York

Gollwitzer P. M., Heckhausen H., (1987), Breadth of Attention and the Counter-Plea Heuristic: Further Evidence on the Motivational vs. Volitional Mindset Distinction, Max-Plank-Institut für psychologische Forshung, München

Howard J.A., (1994), Buyer Behavior in Marketing Strategy, Prentice Hall, Englewood Cliffs

Johnson E.J., Payne J.W., (1985), "Effort and Accuracy", in Management Science, volume 31, n. 4, pp. 395-414

Kahneman D., Tversky A., (1979), "Prospect Theory: An Analysis of Decision under Risk", in Econometrica, volume 47, n. 2, pp. 263-292

Kamleitner B., Kirchler E., (2006), "Personal loan users' mental integration of payment and consumption", in Marketing Letters, volume 17, n. 4, pp. 281-294

Lewis A., van Venrooij M., (1995), "A note on the perceptions of loan duration and repayment", in Journal of Economic Psychology, volume 16, n. 1, pp. 161-168

Lichtenstein S., Slovic P., Fischhoff B., Layman M., Combs B., (1978), "Judged frequency of lethal events", in Journal of Experimental Psychology: Human Learning \& Memory, volume 4, n. 6, pp. 551-578.

Maslow A.H., (1943), "A theory of human motivation", in Psychological Review, volume 50, n. 4, pp. 370-396

Maslow A.H., (1954), Motivation and Personality, Harper, New York

McGuire W.J., (1974), "Psychological motives and communication gratification", in Blumler J.G., Katz C. (Eds.), The Uses of Mass Communication, Sage Publications, Beverly Hills

McGuire W.J., (1976), "Some Internal Psychological Factors Influencing Consumer Choice", in Journal of Consumer Research, volume 2, n. 4, pp. 302-319

Munari L. (1995), "Il sistema di offerta dei servizi bancari", in Scott W.G. (Eds.), Manuale di marketing bancario, UTET, Turin

Murray H.A., (1938), Exploration in Personality, Oxford University Press., London

Murray H.A., (1955), “Types of human needs", in McLelland D. (Eds.), Studies in Motivation, Appleton-Century-Crofts, New York

Olshavsky R.W., Wymer W., (1995), "The desire for new information from external sources", in Mackenzie S., Stayman R. (Eds.), Proceedings of the Society for Consumer Psychology, Printmaster, Bloomington, pp. 17-27

Punj G.N., Staelin R., (1983), “A Model of Consumer Information Search Behavior for New Automobilies", in Journal of Consumer Research, volume 9, n. 4, pp. 366-380 
Ranyard R., Hinkley L.,Williamson J., McHugh S., (2006), "The role of mental accounting in consumer credit decision processes", in Journal of Economic Psychology, volume 27, n. 4, pp. 571-588

Rheinberg F., (2003), Psicologia della motivazione, il Mulino, Bologna

Rumiati R., Bonini N., (1996), Le decisioni degli esperti, il Mulino, Bologna

Rumiati R., Bonini N., (2001), Psicologia della decisione, il Mulino, Bologna

Schaninger M.C., Sciglimpaglia D., (1981), "The Influence of Cognitive Personality Traits and Demographics on Consumer Information Acquisition", in Journal of Consumer Research, volume 8, n. 2, pp. 208-216

Schmidt J.B., Spreng R.A., (1996), "A Proposed Model of External Consumer Information Search", in Journal of Academey of Marketing Science, volume 24, n. 3, pp. 246-256

Simon H.A., (1955), "A Behavioural Model of Rational Choice", in Quaterly Journal of Economics, volume 69, n. 1, pp. 99-118

Solomon M.R., (1996), Consumer Behavior, Prentice Hall, Englewood Cliffs

Srinivasan N., Ratchford B.T., (1991), "An Empirical Test of a Model of External Search for Automobilies", in Journal of Consumer Research, volume 18, n. 2, pp. 233-242

Tagliavini G. (1990), "La gestione dei patrimoni familiari: il ruolo della consulenza", in Economia \& Management, volume 14

Tversky A., (1972), "Elimination by aspects: A theory of choice", in Psychological Review, volume 79, n. 4, pp. 281-299

Williamson J., Ranyard R., Cuthbert L., (2000), "Risk management in everyday insurance decisions: Evidence from a process tracing study", in Risk, Decision and Policy, volume 5, n. 1, pp. 19-38

Wyer R.S., Srull T.K., (1980), "The Processing of Social Stimulus Information: A Conceptual Integration", in Carlston D.E., Ebbesen E.B., Hamilton D.L., Hastie R., Ostrom T.M., Wyer R.S., Person Memory:The Cognitive Basis of Social Perception, Lawrence Erlbaum Associates, Hillsdale, pp. 227-294 